\title{
Early prostate specific antigen decline and its velocity are independent predictive factors for outcomes of MCRPC patients treated with abiraterone acetate
}

\author{
Jiang-Yi Wang ${ }^{1,2,3+} \oplus$, Guo-Peng Yu ${ }^{3+}$, Long Lij ${ }^{3+}$, Guo-Wen Lin ${ }^{1,2^{*}}$ and Ding-Wei Ye $e^{1,2^{*}}$
}

Keywords: Metastatic castration-resistant prostate cancer, PSA decline, PSA velocity, Overall survival, Time to PSA progression

\section{Dear Editor,}

Although the incidence of prostate cancer $(\mathrm{PCa})$ has decreased in recent decades in Western countries, it has gradually increased in China due to the increasingly longer life expectancy and more popular westernized diet [1]. Androgen deprivation therapy (ADT) has been a cornerstone in the treatment of advanced PCa. However, most patients develop resistance to ADT within a median duration of $18-24$ months, which is defined as castration-resistant prostate cancer (CRPC). Abiraterone acetate (AA), an inhibitor of the androgen biosynthesis enzyme CYP17 (17-a-hydroxylase and C17,20-lyase), has been approved for the treatment of metastatic CRPC, although not all patients benefit from AA treatment $[2$, 3]. Therefore, identifying patients who will respond to AA treatment and the time to second-line therapy is of great importance.

In this study, 120 Chinese patients diagnosed with metastatic castration-resistant prostate cancer (mCRPC) who were treated with AA at Fudan University Shanghai

*Correspondence: guowenlin@urocancer.org; dwyeli@163.com

†Jiang-Yi Wang, Guo-Peng Yu and Long Li have contributed equally to this work.

${ }^{1}$ Department of Urology, Fudan University Shanghai Cancer Center, 270 Dong'an Road, Shanghai 200032, China

Full list of author information is available at the end of the article
Cancer Center between April 2012 and February 2018 were recruited. Demographic characteristics, laboratory findings, and clinical outcomes were collected. Early prostate specific antigen (PSA) decline was examined at 4 weeks. The decreased PSA velocity (PSAV) during the first three months of treatment was calculated as the slope of the simple linear regression of PSA (natural scale) versus time. The Kaplan-Meier method with a log-rank test was performed to assess the overall survival (OS) and time to PSA progression (TTPP) of the two groups. Multivariate Cox regression models were used to identify independent risk factors for OS and TTPP. $P<0.05$ (two sides) was considered statistically significant.

The baseline information is shown in Additional file 1: Table S1. The median PSA at diagnosis was $87.0 \mathrm{ng} / \mathrm{ml}$. Patients in the pre-chemotherapy cohort showed a lower PSA value at diagnosis than those in the post-chemotherapy cohort $(80.0 \mathrm{ng} / \mathrm{ml}$ vs. $120.5 \mathrm{ng} / \mathrm{ml}, P=0.036$, Additional file 1: Table S1). A total of 50 (41.7\%) patients reached more than 30\% PSA decline and 30 (25.0\%) patients reached more than $50 \%$ decline at 4 weeks; the median PSAV during the first 12 weeks was $-0.77 \mathrm{ng} /$ (ml-month) (-8.33 to 8.63) (Additional file 1: Table S2).

A rapid PSA decrease during the first 12 weeks $[\mathrm{PSAV}>0.77 \mathrm{ng} /(\mathrm{ml} \cdot \mathrm{month})]$ was associated with a longer OS (30.7 months vs. 22.1 months, $P=0.0023)$ (Additional file 2: Fig. S1 a-c) and a longer TTPP (22.7 months vs. original author(s) and the source, provide a link to the Creative Commons licence, and indicate if changes were made. The images or other third party material in this article are included in the article's Creative Commons licence, unless indicated otherwise in a credit line to the material. If material is not included in the article's Creative Commons licence and your intended use is not permitted by statutory regulation or exceeds the permitted use, you will need to obtain permission directly from the copyright holder. To view a copy of this licence, visit http://creativecommons.org/licenses/by/4.0/. The Creative Commons Public Domain Dedication waiver (http://creativeco mmons.org/publicdomain/zero/1.0/) applies to the data made available in this article, unless otherwise stated in a credit line to the data. 
2.0 months, $P<0.001)$ than PSAV $\leq 0.77 \mathrm{ng} /(\mathrm{ml} \cdot$ month) (Additional file 2: Fig. S1 d-f). The multivariate Cox regression analysis showed that PSAV was an independent risk factor for OS and TTPP in MCRPC patients treated with AA (Additional file 1: Table S3). Meanwhile, patients with more than $30 \%$ early PSA decline showed a longer OS (29.7 months vs. 22.1 months, $P=0.02$, Additional file 2: Fig. S1 g-i) and longer TTPP (22.4 months vs. 3.0 months, $P<0.001$, Additional file 2 : Fig. $S 1 \mathrm{j}-1)$. In the multivariable Cox analysis, less than $30 \%$ early PSA decline and higher baseline PSA at the initiation of treatment were independent risk factors for OS and TTPP (Additional file 1: Table S4).

According to the Prostate Cancer Working Group 3 (PCWG3) criteria, 30\% and 50\% PSA declines at 12 weeks are commonly reported in clinical trials, and both are associated with improved survival [4]. In this study, we found that patients with $30 \%$ early PSA decline showed a longer OS and longer TTPP, which was in line with the findings of a UK cohort [5], and the results were stable for both pre-chemotherapy and post-chemotherapy cohorts. In addition, the PSA decline at 4 weeks was confirmed to be significantly correlated with the PSA change at 12 weeks $(r=0.82, P<0.001)$ [5]. Considering that the clinical practice requires a biomarker of response as early as possible, we suggest that a $30 \%$ PSA decline at 4 weeks should be used as a reliable biomarker to predict the outcome of CRPC patients treated with AA before and after chemotherapy.

The other two predictors of OS were the lowest PSA during previous therapy and baseline PSA at AA initiation. The results suggest that the PSA nadir before AA and baseline PSA at AA initiation should be combined with an early PSA response to help physicians make earlier treatment change decisions. Future studies with a larger cohort are needed to evaluate the synergistic effect of PSA-related biomarkers before, during, and after AA treatment.

The limitations of this study include the retrospective nature and lack of external validation. Moreover, some new drugs that are not available in China have been approved in Western countries, leading to differences in therapeutic strategies between China and other countries. Thus, the conclusion of this study may not be applicable for all patients worldwide, but it will provide valuable information for the treatment of Chinese patients affected by PCa.

\footnotetext{
Abbreviations

AA: Abiraterone acetate; ADT: Androgen deprivation therapy; ALP: Alkaline phosphatase; CRPC: Castration-resistant prostate cancer; LDH: Lactate dehydrogenase; mCRPC: Metastatic castration-resistant prostate cancer; OS: Overall survival; PCa: Prostate cancer; PCWG: Prostate Cancer Working Group; PSA: Prostate-specific antigen; PSAV: PSA velocity; TTPP: Time to PSA progression.
}

\section{Supplementary information}

The online version contains supplementary material available at https://doi. org/10.1186/s40779-021-00364-x.

Additional file 1: Table S1. Characteristics of the MCRPC patients treated with abiraterone acetate (AA). Table S2. PSA changes among patients treated with abiraterone acetate (AA). Table S3. Multivariate COX regression analysis of PSAV for OS and TTPP. Table S4. Multivariate COX regression analysis of early PSA decline for OS and TTPP.

Additional file 2: Fig. S1. The predictive value of PSAV and early PSA change at 4 weeks for OS and TTPP of patients receiving abiraterone therapy. a PSAV for OS in overall cohort; $\mathbf{b}$ PSAV for OS in pre-chemotherapy cohort; c PSAV for OS in post-chemotherapy cohort. d PSAV for TTPP in overall cohort; e PSAV for TTPP in pre-chemotherapy cohort; f PSAV for TTPP in post-chemotherapy cohort. $\mathbf{g}$ Early PSA decline for OS in overall cohort; $\mathbf{h}$ Early PSA decline for OS in pre-chemotherapy cohort; i Early PSA decline for OS in post-chemotherapy cohort. j Early PSA decline for TTPP in overall cohort; $\mathbf{k}$ Early PSA decline for TTPP in pre-chemotherapy cohort; I Early PSA decline for TTPP in post-chemotherapy cohort. OS overall survival, PSA prostate specific antigen, PSAV prostate specific antigen velocity, TTPP time to PSA progression

\section{Acknowledgements}

Not applicable.

\section{Authors' contributions}

DWY and GWL designed this study. JYW, GPY and LL analyzed and interpreted the data. JYW prepared the figures and tables. JYW and GPY drafted the manuscript. DWY and GWL reviewed and revised the manuscript. All authors read and approved the final manuscript.

\section{Funding}

This work was supported by the National Natural Science Foundation of China (81902574), the Shanghai Basic Research Program (19JC1411600), the Shanghai Natural Science Foundation (21ZR1414500), and the Shanghai Sailing Program (19YF1409800).

\section{Availability of data and materials}

The data supporting the conclusions of this article are included within the article.

\section{Declarations}

\section{Ethics approval and consent to participate}

The study protocol was approved by the ethics committee of Fudan University Shanghai Cancer Center. All the research was carried out in line with the provisions of the Declaration of Helsinki of 1975.

Consent for publication

Not applicable.

\section{Competing interests}

The authors declare that they have no competing interests.

\section{Author details}

${ }^{1}$ Department of Urology, Fudan University Shanghai Cancer Center, 270 Dong'an Road, Shanghai 200032, China. '2Department of Oncology, Shanghai Medical College, Fudan University, Shanghai 200032, China. ${ }^{3}$ Department of Urology, Shanghai Ninth People's Hospital, Shanghai Jiaotong University School of Medicine, Shanghai 200011, China.

Received: 12 July 2021 Accepted: 29 December 2021

Published online: 24 January 2022 


\section{References}

1. Bray F, Ferlay J, Soerjomataram I, Siegel RL, Torre LA, Jemal A. Global cancer statistics 2018: GLOBOCAN estimates of incidence and mortality worldwide for 36 cancers in 185 countries. CA Cancer J Clin. 2018;68(6):394-424.

2. Fizazi K, Scher HI, Molina A, Logothetis CJ, Chi KN, Jones RJ, et al. Abiraterone acetate for treatment of metastatic castration-resistant prostate cancer: final overall survival analysis of the COU-AA-301 randomised, double-blind, placebo-controlled phase 3 study. Lancet Oncol. 2012;13(10):983-92.

3. de Bono JS, Logothetis CJ, Molina A, Fizazi K, North S, Chu L, et al. Abiraterone and increased survival in metastatic prostate cancer. N Engl J Med. 2011;364(21):1995-2005.

4. Scher HI, Morris MJ, Stadler WM, Higano C, Basch E, Fizazi K, et al. Trial design and objectives for castration-resistant prostate cancer: updated recommendations from the prostate cancer clinical trials working group 3. J Clin Oncol. 2016;34(12):1402-18.

5. Rescigno P, Lorente D, Bianchini D, Ferraldeschi R, Kolinsky MP, Sideris S, et al. Prostate-specific antigen decline after 4 weeks of treatment with abiraterone acetate and overall survival in patients with metastatic castration-resistant prostate cancer. Eur Urol. 2016;70(5):724-31.

- fast, convenient online submission

- thorough peer review by experienced researchers in your field

- rapid publication on acceptance

- support for research data, including large and complex data types

- gold Open Access which fosters wider collaboration and increased citations

- maximum visibility for your research: over $100 \mathrm{M}$ website views per year

At BMC, research is always in progress.

Learn more biomedcentral.com/submissions 